\title{
Clinical Study \\ Cardiovascular Risk Factors in Bulgarian Patients with Polycystic Ovary Syndrome and/or Obesity
}

\author{
Antoaneta Gateva and Zdravko Kamenov \\ Clinic of Endocrinology, University Hospital Alexandrovska, Medical University-Sofia, 1 Georgi Sofiiski Boulevard, 1431 Sofia, Bulgaria \\ Correspondence should be addressed to Antoaneta Gateva, tony_gateva@yahoo.com
}

Received 31 July 2011; Accepted 10 November 2011

Academic Editor: W. T. Creasman

Copyright ( $) 2012$ A. Gateva and Z. Kamenov. This is an open access article distributed under the Creative Commons Attribution License, which permits unrestricted use, distribution, and reproduction in any medium, provided the original work is properly cited.

Polycystic ovarian syndrome (PCOS) is one of the most common endocrine disturbances in women of reproductive age. Besides its well-known effects on reproductive health, it is also linked to increased cardiovascular risk in later life. The aim of this study is to investigate some classical cardiovascular risk factors in a crossectional study of Bulgarian women with PCOS and/or obesity. We performed a retrospective medical chart review of 375 women from an university endocrine clinic. We found significant differences in the indices of carbohydrate metabolism, blood pressure, lipid profile, rate of liver steatosis, and the levels liver enzymes and hematological results between the lean and obese PCOS women. Obese women without PCOS did not show significantly different results in their OGGT form obese PCOS women. Waist-to-stature-ratio (WSR) correlated better with the baseline IRI levels and lipid profile than waist-to-hip-ratio (WHR) that makes it a better marker for unfavorable metabolic profile.

\section{Introduction}

PCOS is a prevalent disorder that affects approximately 6$10 \%$ of women of reproductive age $[1,2]$ and is a major cause of menstrual disturbances, hirsutism, and female anovulatory infertility. Many PCOS women show evidence of insulin resistance and hyperandrogenism. Current evidence suggests that insulin resistance and compensatory hyperinsulinemia are a central feature of PCOS [3]. Hyperinsulinemia appears to play an important pathogenic role in the hyperandrogenism of both obese and lean women with PCOS [4-6]. According to some studies, PCOS patients have an increased risk for diabetes mellitus $[7,8]$ and often show an adverse cardiovascular risk profile-increased rate of arterial hypertension [9, 10], dislipidemia [10-14], and subclinical inflammation and atherosclerosis [15-17]. Cardiovascular risk factors are usually present even in younger age and this suggests that the chronic disturbances in hormonal and metabolic status typical for the syndrome predispose the patients to development of early atherosclerosis and premature clinical presentation of cardiovascular disease.

Obesity plays an important role in the pathogenesis of PCOS, and around $30-75 \%$ of PCOS women are obese
[18-20]. Over the last 20 years, the prevalence of obesity has dramatically increased, with probable associated increase in PCOS. Obesity contributes to the prevalence of the metabolic syndrome in PCOS patients [21]. Central obesity is often associated with PCOS [22] and carries increased risk for developing cardiovascular disease and type 2 diabetes [23]. The specific indicators of abdominal obesity are better for discriminating the high coronary risk than the usual obesity indicator BMI (body mass index) [24]. In clinical practice waist-to-hip ratio (WHR) has been used to determine the presence of central obesity. There are some indications however that waist-to-stature ratio (WSR) or waist circumference may predict cardiovascular risk better than BMI or WHR [25]. WSR has not been thoroughly studied as a predictor of cardiovascular risk in patients with PCOS. The aim of this study is to investigate some classical cardiovascular risk factors in a crossectional study of Bulgarian women with PCOS and/or obesity.

\section{Materials and Methods}

The sources of information in this study were the available medical charts of the patients referred to the Clinic of 
Endocrinology in Alexandrovska University Hospital-Sofia for the last 21 years (starting year 1990). In this retrospective study were included patients with diagnosed PCOS or obesity that had sufficient data in their medical charts to be included in the analysis.

Electronic database was created that included the following information for each patient.

(1) General Information: name, age, place of residence, date of admittance, hospital stay.

(2) Anthropometric Data: height, weight, body mass index (BMI), waist circumference, hip circumference, waist-to-hip ratio (WHR), waist-to-stature ratio (WSR).

(3) Obesity was accepted at BMI $\geq 30 \mathrm{~kg} / \mathrm{m}^{2}$.

(4) Polycystic Ovary Syndrome was diagnosed according to the ESHRE-ASRM criteria-two out of the following: (1) oligo/amenorrhea; (2) clinical or biochemical hyperandrogenism; (3) polycystic ovaries at ultrasound examination when all other endocrine causes are excluded.

(5) Arterial Hypertension was accepted if there was such a diagnosis in the file and/or there was antihypertensive treatment and/or measured during the hospital stay arterial blood pressure $\geq 140 / 90 \mathrm{mmHg}$. The duration of the hypertension, present blood pressuresystolic (SBP) and diastolic (DBP) number and type of antihypertensive medications were also recorded

(6) Lipid Profile: total cholesterol (TC), HDL-cholesterol (HDL), LDL-cholesterol (LDL), VLDL-cholesterol, triglycerides (TG). Dislipidemia was accepted if there was such a diagnosis in the file and/or there was any treatment for dislipidemia and/or measured during the hospital stay TC > $5.2 \mathrm{mmol} / \mathrm{L}$, and/or $\mathrm{HDL}<$ $1.3 \mathrm{mmol} / \mathrm{L}$ and/or TG $>1.8 \mathrm{mmol} / \mathrm{L}$. The duration of the dislipidemia, present lipid profile, type of treatment and number of medications were also recorded.

(7) Gynecological History: number of pregnancies and births, miscarriages, age of menarche, duration of the menstrual cycle, menstrual disturbances (amenorrhea, oligomenorrhea, hypermenorrhea, polymenorrhea, opsomenorrhea). Regular menstrual cycle was defined as a menstrual cycle between 21 and 35 days and with intercycle variability 2-3 days. Oligomenorrhea was defined as a menstrual cycle longer than 35 days and shorter than 6 months. Amenorrhea was defined as a menstrual cycle longer than 6 months.

(8) Data about the presence of Clinical Hyperandrogenism (hirsutism, acne, androgenic alopecia).

(9) Results form the Oral glucose Tolerance Test (OGTT): blood glucose and imunoreactive insulin (IRI) on 0 , 60 , and $120 \mathrm{~min}$.

(10) Hormonal Status (testosterone, androstendione, dehydroepiandrosteron sulphate (DHEAS), 17-OHprogesterone, estradiol, LH, FSH, TSH, cortisol rhythm, prolactin, etc.).

\section{(11) Liver Enzymes: ASAT, ALAT, GGT, AP}

(12) Hematological Status (after exclusion of actual acute inflammation): hemoglobin, hematocrit, red blood cells (RBC), white blood cells (WBC), mean corpuscular volume (MCV), mean corpuscular hemoglobin $(\mathrm{MCH})$, mean corpuscular hemoglobin concentration (MCHC), mean platelet volume (MPV), erythrocyte sedimentation rate (ESR).

(13) Ultrasound Data for liver steatosis (fatty liver disease).

(14) Gynecological Ultrasound Data: right and left ovary measurements and volume, presence of polycystic ovaries, size of the uterus, endometrium.

(15) ECG Results: heart rate, QT-interval, RR-interval, presence of ischemia.

(16) Data about Medication Use: metformin or combined oral contraceptives (COC) - type and dose.

(17) Data about Ovarian Surgery: wedge resection or endoscopic ovarian drilling.

All laboratory tests were performed in the Central Clinical Laboratory of the Alexandrovska University Hospital in Sofia, which is the reference laboratory for the country. Because in the different periods included in the retrospective study there were some differences in the refference ranges, we used the following formula to unify the data:

$$
Y=a_{0}+\frac{\Delta a\left(x-b_{0}\right)}{\Delta b}
$$

where $Y$ is the standard value; $a_{0}$ is the lower limit of the standard reference range, $b_{0}$ is the lower limit of the given scale, $\Delta a$ is the difference between the upper and the lower limit of the standard reference range.

Hormones from the gonadal axis were measured during the early follicular phase after spontaneous or progestin induced bleeding.

For standard reference range of the hormones were accepted the following:

Testosterone-0.3-3.0 nmol/L,

Androstendione-0.73-10.7 nmol/L,

17-OH-progesterone-0.45-3.3 nmol/L,

DHEAS-1.65-11 mcmol/L,

Estradiol-0.08-0.79 pmol/L,

$\mathrm{LH}-0.7-9.0 \mathrm{mU} / \mathrm{L}$,

FSH-0.6-9.5 mU/L,

Prolactin-50-659 mU/L,

Cortisol 8 o'clock-171-536 nmol/L,

Cortisol 22 o'clock-64-340 nmol/L,

TSH-0.2-4.2 $\mathrm{mU} / \mathrm{L}$.

In the study, were included premenopuasal women with obesity and/or PCOS. Exclusion criteria were considered as age less than 18 or higher than 45 years, postmenopausal state, severe hepatic, cardiovascular or endocrine disorders (incl. diabetes), or other concurrent medical illnesses. The patients were divided into three groups-group 1 Obese; group 2 Lean PCOS, and group 3 Obese PCOS. Comparison was made between the data from these three groups. 
TABLE 1: Anthropometric characteristics of the groups.

\begin{tabular}{lccc}
\hline & $\begin{array}{c}\text { Group } 1 \\
\text { Obese } \\
(n=125)\end{array}$ & $\begin{array}{c}\text { Group 2 } \\
\text { Lean PCOS } \\
(n=94)\end{array}$ & $\begin{array}{c}\text { Group 3 } \\
\text { Obese PCOS } \\
(n=82)\end{array}$ \\
\hline Age (years) & $26.50 \pm 5.47$ & $25.17 \pm 4.64$ & $26.26 \pm 5.64$ \\
Height $(\mathrm{cm})$ & $162.99 \pm 6.09$ & $163.39 \pm 6.52$ & $163.68 \pm 6.70$ \\
Weight $(\mathrm{kg})$ & $99.82 \pm 17.00^{\wedge \wedge \wedge}$ & $61.56 \pm 10.32^{* * *}$ & $97.09 \pm 14.07$ \\
BMI $\left(\mathrm{kg} / \mathrm{m}^{2}\right)$ & $37.55 \pm 5.95^{\wedge \wedge \wedge}$ & $23.04 \pm 3.47^{* * *}$ & $36.21 \pm 4.58$ \\
Waist $(\mathrm{cm})$ & $106.92 \pm 12.49^{\wedge \wedge \wedge}$ & $77.81 \pm 9.87^{* * *}$ & $103.69 \pm 10.24$ \\
Hip $(\mathrm{cm})$ & $121.78 \pm 11.70^{\wedge \wedge \wedge}$ & $96.93 \pm 8.34^{* * *}$ & $118.92 \pm 9.39$ \\
WHR & $0.86 \pm 0.08^{\wedge \wedge \wedge}$ & $0.79 \pm 0.06^{* * *}$ & $0.87 \pm 0.08$ \\
WSR & $0.65 \pm 0.08^{\wedge \wedge \wedge}$ & $0.47 \pm 0.06^{* * *}$ & $0.63 \pm 0.07$ \\
\hline
\end{tabular}

${ }^{* * *} P<0.001$ between group 2 and group 3 .

$\wedge \wedge \wedge P<0.001$ between group 1 and group 2 .

TABLE 2: Comparison between the results from oral glucose tolerance test, lipid profile, blood pressure measurement, and ECG characteristics between the three groups.

\begin{tabular}{|c|c|c|c|c|c|c|}
\hline & \multicolumn{2}{|r|}{$\begin{array}{l}\text { Group } 1 \\
\text { Obese }\end{array}$} & \multicolumn{2}{|r|}{$\begin{array}{c}\text { Group } 2 \\
\text { Lean PCOS }\end{array}$} & \multicolumn{2}{|c|}{$\begin{array}{c}\text { Group } 3 \\
\text { Obese PCOS }\end{array}$} \\
\hline & $n$ & & $n$ & & $n$ & \\
\hline Fasting blood glucose (mmol/L) & 125 & $4.37 \pm 1.02$ & 94 & $4.25 \pm 0.75^{*}$ & 82 & $4.63 \pm 0.94$ \\
\hline Blood glucose on $60 \mathrm{~min}$ of OGTT $(\mathrm{mmol} / \mathrm{L})$ & 110 & $7.62 \pm 1.99^{\wedge}$ & 75 & $6.72 \pm 2.08^{* *}$ & 78 & $7.87 \pm 2.09$ \\
\hline Blood glucose on $120 \mathrm{~min}$ of OGTT $(\mathrm{mmol} / \mathrm{L})$ & 119 & $5.86 \pm 1.62$ & 74 & $5.70 \pm 1.45$ & 81 & $6.06 \pm 1.54$ \\
\hline Fasting IRI (mU/L) & 86 & $18.24 \pm 9.86^{\wedge \wedge \wedge}$ & 72 & $8.16 \pm 4.22^{* * *}$ & 69 & $20.35 \pm 11.67$ \\
\hline IRI on $60 \mathrm{~min}$ of OGTT (mU/L) & 54 & $108.70 \pm 78.26^{\wedge \wedge}$ & 62 & $65.50 \pm 49.05^{* * *}$ & 54 & $129.26 \pm 79.32$ \\
\hline IRI on $120 \mathrm{~min}$ of OGTT $(\mathrm{mU} / \mathrm{L})$ & 57 & $66.69 \pm 50.11^{\wedge}$ & 61 & $39.40 \pm 33.11^{* * *}$ & 53 & $90.22 \pm 74.22$ \\
\hline HOMA index & 86 & $3.80 \pm 2.41^{\wedge \wedge \wedge}$ & 72 & $1.56 \pm 0.97^{* * *}$ & 68 & $4.32 \pm 2.69$ \\
\hline Fasting glucose/insulin ratio & 86 & $0.34 \pm 0.22^{\wedge \wedge \wedge}$ & 72 & $0.68 \pm 0.39^{* * *}$ & 68 & $0.32 \pm 0.22$ \\
\hline Dislipidemia (\%) & 125 & $44.0 \% \%^{\wedge \wedge \wedge}$ & 91 & $15.4 \% * * *$ & 81 & $40.7 \%$ \\
\hline Treatment for dislipidemia (\%) & 125 & $4.8 \%$ & 91 & $1.1 \%$ & 80 & $2.5 \%$ \\
\hline Total cholesterol (mmol/L) & 122 & $4.73 \pm 0.94$ & 89 & $4.60 \pm 0.97$ & 81 & $4.68 \pm 0.81$ \\
\hline HDL cholesterol (mmol/L) & 95 & $1.27 \pm 0.28^{\wedge \wedge \wedge}$ & 52 & $1.52 \pm 0.40^{* *}$ & 66 & $1.28 \pm 0.34$ \\
\hline LDL cholesterol (mmol/L) & 95 & $2.73 \pm 0.88$ & 52 & $2.78 \pm 0.94$ & 65 & $2.64 \pm 0.73$ \\
\hline VLDL cholesterol (mmol/L) & 94 & $0.67 \pm 0.43^{\wedge \wedge \wedge}$ & 49 & $0.37 \pm 0.18^{* * *}$ & 64 & $0.71 \pm 0.43$ \\
\hline Triglycerides $(\mathrm{mmol} / \mathrm{L})$ & 125 & $1.76 \pm 0.75^{\wedge \wedge \wedge}$ & 89 & $0.91 \pm 0.37^{* * *}$ & 80 & $1.56 \pm 0.72$ \\
\hline Arterial hypertension (\%) & 125 & $31.2 \% \wedge \wedge \wedge$ & 93 & $1.1 \%{ }^{* * *}$ & 81 & $29.6 \%$ \\
\hline Treatment for arterial hypertention (\%) & 125 & $12.8 \% \wedge \wedge$ & 93 & $1.1 \% * * *$ & 81 & $18.5 \%$ \\
\hline Systolic blood pressure (mmHg) & 125 & $124.00 \pm 12.44^{\wedge \wedge \wedge}$ & 90 & $113.78 \pm 12.09^{* * *}$ & 81 & $123.77 \pm 14.41$ \\
\hline Diastolic blood pressure (mmHg) & 125 & $80.00 \pm 9.20^{\wedge \wedge \wedge}$ & 90 & $73.11 \pm 8.16^{* * *}$ & 81 & $80.06 \pm 10.29$ \\
\hline cQT-interval (sec) & 19 & $0.41 \pm 0.02$ & 9 & $0.41 \pm 0.04$ & 18 & $0.40 \pm 0.03$ \\
\hline RR-interval (sec) & 22 & $0.73 \pm 0.13^{\wedge \wedge}$ & 9 & $0.89 \pm 0.16^{*}$ & 19 & $0.74 \pm 0.09$ \\
\hline Heart rate (bpm) & 27 & $84.48 \pm 11.46^{\wedge \wedge \wedge}$ & 9 & $68.22 \pm 9.64^{*}$ & 25 & $79.48 \pm 8.95$ \\
\hline
\end{tabular}

${ }^{*} P<0.05 ;{ }^{* *} P<0.01 ;{ }^{* * *} P<0.001$ between group 2 and group 3 .

${ }^{\wedge} P<0.05 ;^{\wedge \wedge} P<0.01 ;^{\wedge \wedge} P P<0.001$ between group 1 and group 2 .

$n=$ number of patients.

As a part of this retrospective study, we performed an analysis of the data from the OGTT using different criteria for insulin resistance:

(1) elevated baseline IRI,

(2) decreased baseline glucose/insulin ratio (less than $0.333 \mathrm{mmol} / \mathrm{L} / \mathrm{mU} / \mathrm{L})$,
(3) increase of the level of the IRI more than $100 \mathrm{mU} / \mathrm{L}$ during the OGTT,

(4) increase of the level of the IRI more than 5 times from the baseline,

(5) HOMA index more than 2.0, calculated as baseline blood glucose $(\mathrm{mmol} / \mathrm{L})$ multiplied by baseline IRI $(\mathrm{mU} / \mathrm{L})$ and then devided by 22.5 . 
TABLE 3: Comparison between liver enzymes and the rate of liver steatosis and the blood count between the three groups.

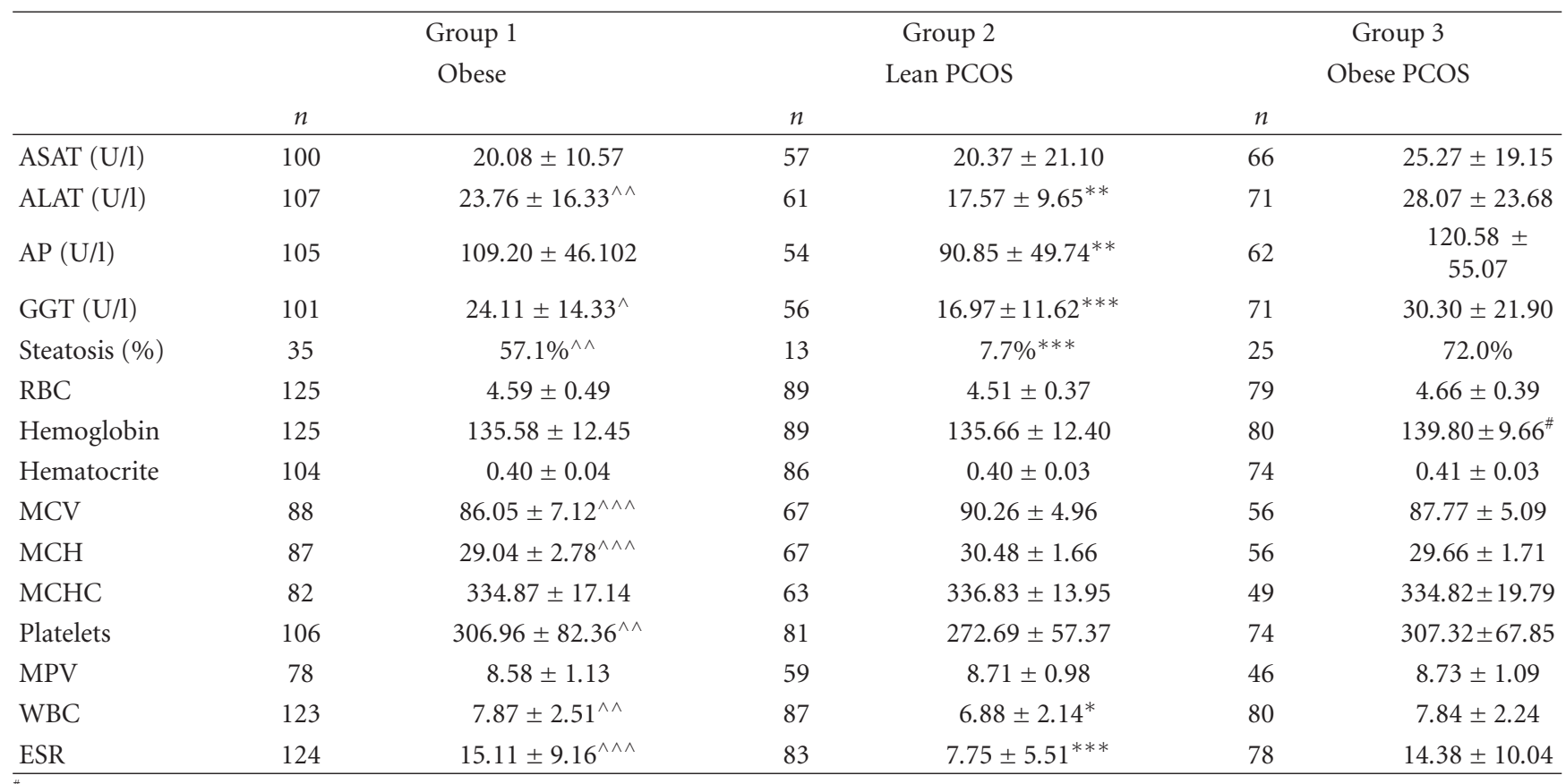

${ }^{\#} P<0.05$; between group 1and group 3 .

${ }^{*} P<0.05 ; * * P<0.01 ; * * * P<0.001$ between group 2 and group 3 .

${ }^{\wedge} P<0.05 ; \wedge \wedge P<0.01 ; \wedge \wedge \wedge P<0.001$ between group 1 and group 2 .

$n=$ number of patients.

For this part of the study were used only the patients that had the full data from the OGTT (blood glucose on 0,60 and $120 \mathrm{~min}$ and IRI on 0, 60, and $120 \mathrm{~min}$ ). For every patient were examined the presence of insulin resistance by each of these criteria and its prevalence in the general group and separately in each subgroup.

2.1. Statistical Methods. The data were processed using the statistical package SPSS 16.0. The level of significance for rejecting the null hypothesis was $P<0.05$. The following statistical methods were applied: descriptive analysis, variation analysis, Kolmogorov-Smirnov's one sample nonparametric test, Student's $t$-test for two independent samples, Kruskal-Wallis' nonparametric test for several independent samples, Mann-Whitney's nonparametric test for two independent samples, one-way analysis of variance betweengroups ANOVA with post hoc tests, and correlation analysis.

\section{Results}

Initially the present study included 375 women. After agematching of the three groups, 74 women with obesity were excluded and at the end 301 women aged 18 to 40 years participated in the analysis. Patients' characteristics are shown in Table 1.

Obese PCOS women did not significantly differ in weight, BMI, waist, hip, WHR, or WSR from the obese women without PCOS.

The results from the comparison between the three groups are shown on Tables 2-7. A statically significant difference was found regarding the results from the OGTT (blood glucose on 0 and $60 \mathrm{~min}$ and IRI on 0,60 , and $120 \mathrm{~min})$, HOMA-index, glucose/insulin ratio, the rate of hypertension and dislipidemia, systolic and diastolic blood pressure, HDL, VLDL, and TG (Table 2), the rate of liver steatosis and the levels of ALAT, GGT, and AP, and hematological results (WBC and ESR) (Table 3 ) between the lean and obese PCOS women.

Obese women without PCOS did not show significantly different results in their OGTT form obese PCOS women. These two groups however differ in the levels of testosterone and LH, ovarian volume (Table 4) and the rate of hirsutism (Table 6) and menstrual disturbances (length of menstrual cycle and the prevalence of oligomenorrhea).

A strong positive correlation was found between the body weight and baseline IRI and HOMA index in general $(r=$ 0.58 and $r=0.59$, resp., $P<0.01$ ) that is most prominent in lean PCOS group. The correlation is weaker for IRI on 60 and 120 min of OGTT $(r=0.25$ and $r=0.14$, resp., $P<0.01)$. It is worth mentioning that WSR correlates better with the baseline IRI levels and HOMA-index $(r=0.31$ and $r=0.59$, resp., $P<0.05)$ than WHR $(r=0.18$ and $r=0.38$, resp., $P<$ 0.05 ) that makes it a better marker for unfavorable metabolic profile.

A weak but statistically significant correlation was observed in the total group between the results from the OGTT (except fasting blood glucose) and systolic and diastolic blood pressure that disappear when patients are divided into groups according to diagnosis, except for the intermediate correlation that exists between SBP, DBP, and blood glucose on $120 \mathrm{~min}(r=0.263$ and $r=0.224, P<0.05)$ IRI on 
TABLE 4: Comparison of hormone levels and the indices of ovarian function between the three groups.

\begin{tabular}{|c|c|c|c|c|c|c|}
\hline & \multicolumn{2}{|r|}{$\begin{array}{l}\text { Group } 1 \\
\text { Obese }\end{array}$} & \multicolumn{2}{|c|}{$\begin{array}{c}\text { Group } 2 \\
\text { Lean PCOS }\end{array}$} & \multicolumn{2}{|c|}{$\begin{array}{c}\text { Group } 3 \\
\text { Obese PCOS }\end{array}$} \\
\hline & $n$ & & $n$ & & $n$ & \\
\hline Testosterone (nmol/L) & 53 & $2.03 \pm 1.22$ & 85 & $2.42 \pm 1.51$ & 67 & $2.94 \pm 1.72^{\# \#}$ \\
\hline Estradiol (pmol/L) & 37 & $0.39 \pm 0.34$ & 62 & $0.45 \pm 0.47$ & 40 & $0.72 \pm 1.50$ \\
\hline Androstendione (nmol/L) & 17 & $11.58 \pm 9.32$ & 48 & $13.16 \pm 9.33$ & 33 & $13.34 \pm 7.53$ \\
\hline DHEAS $(\mathrm{mcmol} / \mathrm{L})$ & 24 & $7.32 \pm 4.29$ & 60 & $9.24 \pm 4.76$ & 54 & $9.49 \pm 4.98$ \\
\hline 17-OH-progesteron (nmol/L) & 16 & $2.50 \pm 1.45$ & 37 & $3.40 \pm 2.93$ & 38 & $3.49 \pm 2.76$ \\
\hline $\mathrm{LH}(\mathrm{U} / \mathrm{L})$ & 42 & $2.91 \pm 1.85^{\wedge \wedge \wedge}$ & 74 & $5.74 \pm 4.01$ & 59 & $5.17 \pm 4.25^{\# \#}$ \\
\hline FSH (U/L) & 42 & $3.33 \pm 1.94$ & 76 & $3.40 \pm 2.07$ & 60 & $3.25 \pm 1.81$ \\
\hline Prolactin (U/L) & 47 & $355.19 \pm 235.88$ & 54 & $388.45 \pm 241.52$ & 49 & $310.65 \pm 184.77$ \\
\hline Cortisol 8:00 o'clock (nmol/L) & 52 & $405.14 \pm 119.38$ & 30 & $414.67 \pm 156.03$ & 41 & $392.35 \pm 134.26$ \\
\hline Cortisol 22:00 o'clock (nmol/L) & 44 & $103.35 \pm 97.67$ & 15 & $111.37 \pm 39.19$ & 29 & $138.44 \pm 113.19$ \\
\hline $\mathrm{TSH}(\mathrm{U} / \mathrm{L})$ & 62 & $2.09 \pm 0.99$ & 39 & $2.02 \pm 1.51$ & 45 & $1.84 \pm 1.17$ \\
\hline Presence of polycystic ovaries (PCO) (\%) & 31 & $16.1 \%^{\wedge \wedge \wedge}$ & 85 & $84.7 \%$ & 62 & $79.0 \% \# \#$ \\
\hline Right ovary PCO $(\%)$ & 29 & $17.2 \% \%^{\wedge \wedge \wedge}$ & 74 & $87.8 \%$ & 56 & $67.9 \% \#^{\# \#}$ \\
\hline Left ovary PCO (\%) & 29 & $13.8 \% \%^{\wedge \wedge \wedge}$ & 77 & $74.0 \%$ & 56 & $75.0 \% \%^{\# \#}$ \\
\hline Right ovary volume $(\mathrm{mL})$ & 18 & $6.99 \pm 3.36^{\wedge \wedge}$ & 54 & $11.75 \pm 6.16$ & 37 & $10.37 \pm 5.94$ \\
\hline Left ovary volume (mL) & 20 & $4.87 \pm 3.06^{\wedge \wedge}$ & 54 & $9.18 \pm 4.46^{* * *}$ & 35 & $11.13 \pm 6.16$ \\
\hline Age of menarche (years) & 87 & $12.73 \pm 1.66$ & 86 & $13.05 \pm 1.74$ & 69 & $12.66 \pm 1.62$ \\
\hline Length of menstrual cycle (days) & 44 & $29.55 \pm 6.01^{\wedge \wedge \wedge}$ & 56 & $51.14 \pm 23.12^{*}$ & 30 & $40.87 \pm 16.86^{\# \#}$ \\
\hline Duration of menstrual bleeding (days) & 33 & $4.88 \pm 2.84$ & 44 & $4.95 \pm 1.09$ & 22 & $6.27 \pm 5.55$ \\
\hline Rate of menstrual disturbances (\%) & 107 & $39.3 \% \wedge \wedge \wedge$ & 92 & $78.3 \%$ & 79 & $81.0 \%$ \%\#\# \\
\hline Regular menstrual cycle (\%) & 106 & $65.1 \% \%^{\wedge \wedge \wedge}$ & 93 & $23.7 \%$ & 80 & $20.0 \%{ }^{\# \# \#}$ \\
\hline Oligiomenorrhea (\%) & 104 & $28.8 \% \%^{\wedge \wedge \wedge}$ & 93 & $66.7 \%$ & 80 & $66.2 \%{ }^{\# \# \#}$ \\
\hline Hypermenorrhea (\%) & 103 & $6.8 \%$ & 91 & $3.3 \%$ & 80 & $7.5 \%$ \\
\hline Polymenorrhea (\%) & 103 & $2.9 \%$ & 92 & $0 \%$ & 80 & $1.2 \%$ \\
\hline Opsomenorrhea (\%) & 103 & $3.9 \%$ & 92 & $3.3 \%$ & 80 & $2.5 \%$ \\
\hline Amenorrhea (\%) & 103 & $5.8 \%$ & 92 & $10.9 \%$ & 80 & $13.8 \%$ \\
\hline Pregnancies & 98 & $0.59 \pm 0.77^{\wedge \wedge \wedge}$ & 87 & $0.15 \pm 0.45$ & 81 & $0.42 \pm 0.78$ \\
\hline Births & 97 & $0.51 \pm 0.71^{\wedge \wedge \wedge}$ & 87 & $0.10 \pm 0.34^{*}$ & 81 & $0.31 \pm 0.63$ \\
\hline Miscarriages & 89 & $0.07 \pm 0.36$ & 86 & $0.05 \pm 0.26$ & 78 & $0.08 \pm 0.35$ \\
\hline Rate of infertility (\%) & 40 & $25.0 \%^{\wedge}$ & 20 & $55.0 \%$ & 28 & $50.0 \%$ \\
\hline
\end{tabular}

${ }^{\# \#} P<0.01 ; \# \# P<0.001$ between group 1 and group 3.

${ }^{*} P<0.05$; ${ }^{*} P<0.01$; $* * * P<0.001$ between group 2 and group 3 .

${ }^{\wedge} P<0.05 ; \wedge \wedge P<0.01 ; \wedge \wedge \wedge P<0.001$ between group 1 and group 2 .

$n=$ number of patients.

$120 \min (r=0.438$ and $r=0.428, P<0.05)$ only in obese PCOS patients. Again, WSR correlates better with SBP, DBP, and the rate of hypertension than WHR $(r=0.286$, $r=0.263$, and $r=0.198$, resp., versus $r=0.136, r=0.135$, and $r=0.032$, resp., $P<0.05)$.

Differences in HDL-cholesterol, VLDL-cholesterol, and triglycerides were found between the lean PCOS patients and the other two groups. There is an intermediate correlation between the body weight and the levels of triglycerides $(r=$ $0.39, P<0.01)$ that after dividing the patients into groups persisted only in the lean PCOS group. Only in these patients, we observe a negative correlation between HDL-cholesterol and body weight $(r=-0.45, P<0.01)$. The same as for carbohydrate metabolism, WSR also shows stronger correlation than WHR with the levels of HDL $(r=-0.27$ versus $r=-0.10)$, VLDL-choleserol $(r=0.38$ versus $r=$ $0.29, P<0.05)$, and TG $(r=0.41$ versus $r=0.27, P<0.05)$ but not with TC ( $r=0.03$ versus $r=0.14)$.

As for liver function, the levels of the liver enzymes and the rate of liver stetaosis are significantly lower in the lean PCOS patients. A strong correlation between the body weight and the presence of liver steatosis $(r=0.56, P<0.01)$ was found so we can say that the main factor for development of nonalcoholic fatty liver disease is the obesity. The levels of GGT but not ASAT, ALAT, or AP correlate with IRI on 0 and $60 \mathrm{~min}$ and HOMA index. The rate of liver steatosis also shows good correlation with IRI during the OGTT, HOMA index, glucose/insulin ratio, and diastolic blood pressure. 
TABLE 5: Comparison between the family history for chronic diseases between the three groups.

\begin{tabular}{|c|c|c|c|c|c|c|}
\hline & \multicolumn{2}{|c|}{$\begin{array}{l}\text { Group } 1 \\
\text { Obese }\end{array}$} & \multicolumn{2}{|c|}{$\begin{array}{c}\text { Group } 2 \\
\text { Lean PCOS }\end{array}$} & \multicolumn{2}{|c|}{$\begin{array}{c}\text { Group } 3 \\
\text { Obese PCOS }\end{array}$} \\
\hline & $n$ & & $n$ & & $n$ & \\
\hline Diabetes mellitus (\%) & 106 & $40.6 \% \wedge$ & 79 & $24.1 \% *$ & 75 & $42.7 \%$ \\
\hline Arterial hypertension (\%) & 106 & $38.7 \% \%^{\wedge \wedge}$ & 79 & $19.0 \% *$ & 75 & $37.3 \%$ \\
\hline Dislipidema (\%) & 105 & $0.9 \%$ & 79 & $0 \%$ & 75 & $0 \%$ \\
\hline Obesity (\%) & 106 & $28.3 \% \%^{\wedge \wedge \wedge}$ & 79 & $1.3 \% * * *$ & 75 & $25.3 \%$ \\
\hline CHD (coronary heart disease) (\%) & 106 & $0.9 \%$ & 79 & $1.3 \%$ & 75 & $5.3 \%$ \\
\hline Menstrual disturbances (\%) & 106 & $0.9 \%$ & 79 & $3.8 \%$ & 75 & $1.3 \%$ \\
\hline $\operatorname{PCOS}(\%)$ & 106 & $0 \%{ }^{\wedge \wedge \wedge}$ & 79 & $12.7 \% *$ & 74 & $2.7 \%$ \\
\hline
\end{tabular}

${ }^{*} P<0.05 ;{ }^{* *} P<0.01 ;{ }^{* * *} P<0.001$ between group 2 and group 3 .

${ }^{\wedge} P<0.05 ; \wedge \wedge P<0.01 ; \wedge \wedge \wedge P<0.001$ between group 1 and group 2 .

$n=$ number of patients.

TABLE 6: Comparison between the data about clinical hyperandrogenism between the three groups.

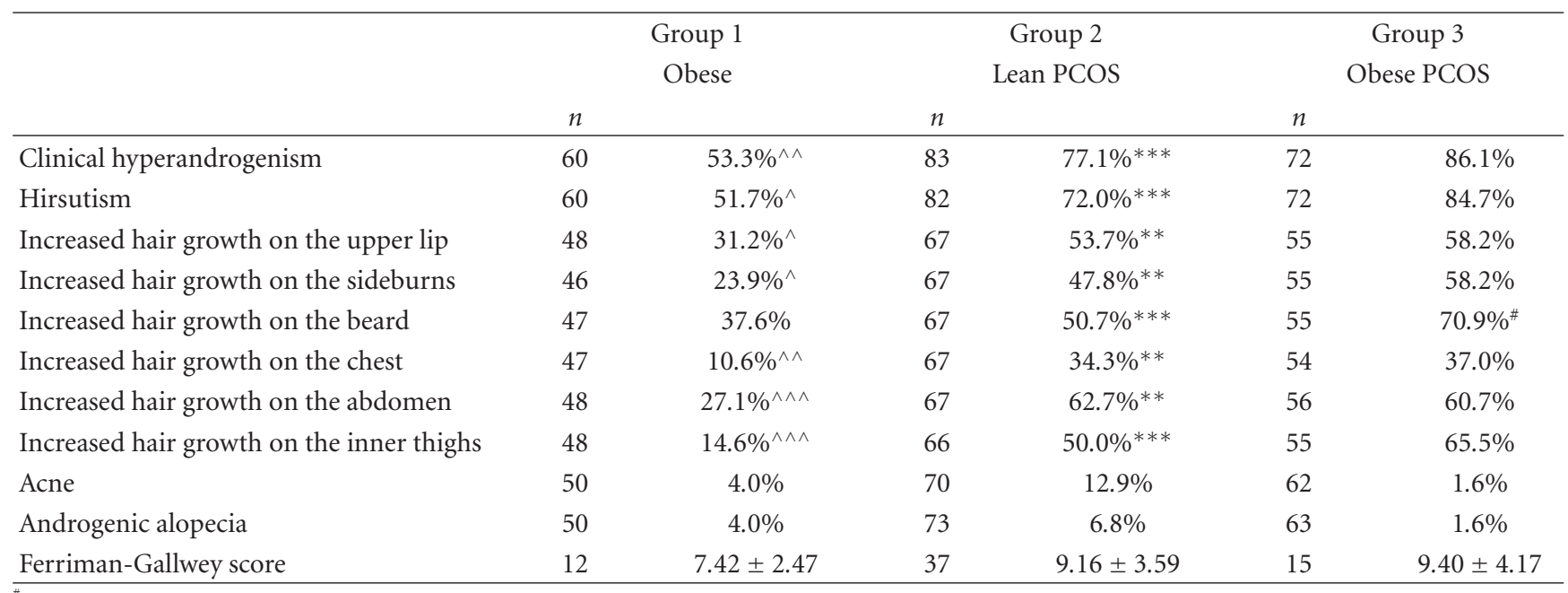

${ }^{\#} P<0.05$; between group 1 and group 3 .

${ }^{*} P<0.05 ;{ }^{* *} P<0.01$; ${ }^{* * *} P<0.001$ between group 2 and group 3 .

${ }^{\wedge} P<0.05 ;{ }^{\wedge} P<<0.01 ;{ }^{\wedge \wedge} P P<0.001$ between group 1 and group 2 .

$n=$ number of patients.

WBC showed correlation with baseline blood glucose and HOMA index $(r=0.340$ and $0.410 ; P<0.05)$ but not with the results during OGTT. There is also intermediate correlation between WBC and VLDL and TG-levels $(r=$ 0.358 and 0.333 , resp., $P<0.01$ ). On the other hand, ESR also shows good correlation to HOMA index, BMI, WHR, and WSR $(r=0.360 ; r=0.441 ; r=0.242 ; r=0.397$; $P<0.01)$ and not to any of the androgen levels.

The levels of testosterone and androstendione did not show significant correlation to the results of OGTT, lipid levels, blood pressure, liver enzymes, or blood count in the total group. Hemoglobin and hematocirte show a weak positive correlation to the testosterone levels $(r=0.239$ and $r=0.199$ ) but not to the levels of other androgens.

Interestingly, obese PCOS patients have significantly higher rate of family history for coronary heart disease compared to the other two groups (Table 8). Lean PCOS patients have higher rate of family history of PCOS than obese PCOS patients. On the other hand, obese patients with or without
PCOS have higher rate of family history for diabetes mellitus, hypertension, and obesity than lean patients.

As expected, the main reason for admittance of the obese patients without PCOS is obesity per se while for the other two groups the leading reason are menstrual disturbances followed by hirsutism. However, menstrual disturbances as a reason for admittance are significantly more common in lean PCOS patients than in obese PCOS patients.

The use of metformin is most frequent in the obese PCOS group and does not significantly differ between the other two groups (Table 7). That can be explained by the more prominent insulin resistance in patients that have both obesity and PCOS. It must be noted, however, that lean PCOS patients start insulin sensitizing therapy as frequent as obese women without the syndrome. There still remains opened the question how is insulin resistance detected in every single patient (Table 8).

Of 375 women in our study 155 had the full set of data from the OGTT (blood glucose and IRI on 0, 60, 
TABle 7: Comparison between the reasons for admittance and the type of treatment before and after the admittance between the three groups.

\begin{tabular}{|c|c|c|c|c|c|c|}
\hline & \multicolumn{2}{|r|}{$\begin{array}{l}\text { Group } 1 \\
\text { Obese }\end{array}$} & \multicolumn{2}{|c|}{$\begin{array}{c}\text { Group } 2 \\
\text { Lean PCOS }\end{array}$} & \multicolumn{2}{|c|}{$\begin{array}{c}\text { Group } 3 \\
\text { Obese PCOS }\end{array}$} \\
\hline & $n$ & & $n$ & & $n$ & \\
\hline Hirsutism & 125 & $4.0 \%{ }^{\wedge \wedge \wedge}$ & 92 & $42.4 \%$ & 79 & $35.4 \%{ }^{\# \# \#}$ \\
\hline Menstrual disturbances & 125 & $9.6 \% \%^{\wedge \wedge \wedge}$ & 92 & $75.0 \% * *$ & 79 & $49.4 \% \# \#$ \\
\hline Infertility & 125 & $4.0 \%$ & 92 & $4.3 \%$ & 79 & $8.9 \%$ \\
\hline Obesity & 125 & $72.0 \% \wedge \wedge \wedge$ & 92 & $4.3 \% * * *$ & 79 & $49.4 \% \%^{\# \#}$ \\
\hline Other & 124 & $20.2 \%^{\wedge}$ & 92 & $9.8 \%$ & 79 & $7.6 \% \#$ \\
\hline Mean hospital stay (days) & 125 & $8.42 \pm 5.47^{\wedge}$ & 94 & $6.51 \pm 4.37$ & 82 & $7.89 \pm 4.78$ \\
\hline COC before the admittance & 125 & $4.8 \% \%^{\wedge \wedge \wedge}$ & 92 & $46.7 \% * * *$ & 78 & $34.6 \%$ \\
\hline Metformin before the admittance & 125 & $10.4 \%$ & 92 & $7.6 \%$ & 78 & $17.9 \%{ }^{\#}$ \\
\hline $\begin{array}{l}\text { Combination of COC and metformin before } \\
\text { the admittance }\end{array}$ & 125 & $0 \%$ & 92 & $0 \% * *$ & 65 & $7.7 \% \#$ \\
\hline Surgical treatment before the admittance & 125 & $0 \% \wedge \wedge$ & 92 & $6.5 \% * *$ & 78 & $7.7 \%$ \\
\hline COC after the admittance & 125 & $4.8 \% \%^{\wedge \wedge \wedge}$ & 92 & $28.3 \% * * *$ & 78 & $28.2 \%$ \\
\hline Metformin after the admittance & 125 & $48.8 \%$ & 92 & $44.6 \% \%^{* * *}$ & 78 & $78.2 \% \# \#$ \\
\hline $\begin{array}{l}\text { Combination of COC and metformin before } \\
\text { the admittance }\end{array}$ & 125 & $1.6 \% \%^{\wedge \wedge \wedge}$ & 92 & $8.7 \% * * *$ & 78 & $19.2 \%{ }^{\#}$ \\
\hline Surgical treatment after the admittance & 125 & $0 \%$ & 92 & $0 \%$ & 78 & $0 \%$ \\
\hline
\end{tabular}

${ }^{\#} P<0.05 ; \# P<0.01 ;{ }^{\# \#} P<0.001$ between group 1 and group 3 .

${ }^{*} P<0.05 ;{ }^{* *} P<0.01 ;{ }^{* * *} P<0.001$ between group 2 and group 3 .

${ }^{\wedge} P<0.05 ;^{\wedge \wedge} P<0.01 ;^{\wedge \wedge} \wedge P<0.001$ between group 1 and group 2 .

$n=$ number of patients.

TABLE 8: Insulin resistance according to different criteria in the general group $(n=155)$.

\begin{tabular}{|c|c|c|}
\hline & Number & $\begin{array}{c}\% \text { from the total } \\
\text { number }\end{array}$ \\
\hline IFG/IGT & 20 & $12.9 \%$ \\
\hline Increased baseline insulin & 62 & $40.0 \%$ \\
\hline $\begin{array}{l}\text { Elevation of IRI over } 100 \mathrm{mU} / \mathrm{L} \text { on } \\
\text { the } 60 \mathrm{~min} \text { of OGTT }\end{array}$ & 62 & $40.0 \%$ \\
\hline $\begin{array}{l}\text { Elevation of IRI over } 100 \mathrm{mU} / \mathrm{L} \text { on } \\
\text { the } 120 \mathrm{~min} \text { of OGTT }\end{array}$ & 28 & $18.1 \%$ \\
\hline $\begin{array}{l}\text { Elevation of IRI over } 100 \mathrm{mU} / \mathrm{L} \text { on } \\
\text { the } 60 \text { and/or } 120 \mathrm{~min} \text { of OGTT }\end{array}$ & 66 & $42.6 \%$ \\
\hline $\begin{array}{l}\text { Elevation of IRI over } 100 \mathrm{mU} / \mathrm{L} \text { on } \\
\text { the } 60 \text { and } 120 \mathrm{~min} \text { of OGTT }\end{array}$ & 24 & $15.5 \%$ \\
\hline $\begin{array}{l}\text { Elevation of IRI more than } 5 \text { times } \\
\text { over the baseline }\end{array}$ & 108 & $69.7 \%$ \\
\hline $\begin{array}{l}\text { Decreased baseline glucose/insulin } \\
\text { ratio }(<0.333 \mathrm{mmol} / \mathrm{L} / \mathrm{mU} / \mathrm{L})\end{array}$ & 71 & $45.8 \%$ \\
\hline Increased HOMA-index (\%) & 93 & $60.0 \%$ \\
\hline
\end{tabular}

and $120 \mathrm{~min}$ ). In every one of them, we assessed the presence or the lack of impaired fasting glucose, glucose tolerance, or insulin resistance according to these criteria.

The presence of insulin resistance using the increased baseline insulin or insulin elevation over $100 \mathrm{mU} / \mathrm{L}$ during the OGTT correlates better with the arterial blood pressure and lipid levels than when using elevation of IRI more than 5 times over the baseline (Table 9 ).
These data show a lower level of insulin resistance in lean PCOS subjects compared to the other groups. There is also a different rate of insulin resistance when using different criteria in the total group and in every subgroup. In the three groups, there is a higher rate of insulin resistance when using the elevation of IRI more than 5 times over the baseline. In this case, the rate of insulin resistance in the three groups is similar. It should be noted, however, that the highest elevation of IRI is seen in some patients on the $60 \mathrm{~min}$ of OGTT and in others on $120 \mathrm{~min}$ of the OGTT. For this reason to benefit from the full diagnostic power of the method, it is necessary to measure IRI both on 60 and $120 \mathrm{~min}$, otherwise, we would miss patients with insulin resistance.

\section{Discussion}

The aim of the study was to investigate some cardiovascular risk factors in young women with PCOS. This is the largest study on PCOS patients in Bulgaria.

The link between the obesity and reproductive problems in women has been studied for a long time and is confirmed from the results of a number of epidemiological and clinical studies (for review [26]). The rate of obesity in patients with PCOS is between $30 \%$ and $70 \%$ depending on the ethnicity and the used criteria for diagnosis of PCOS $[27,28]$. Therefore, PCOS patients can be divided into two main phenotypes according to their BMI-lean and obese that have very different metabolic and cardiovascular risk profile. Although the insulin resistance is thought to be fundamental 
TABLE 9: Insulin resistance according to different criteria.

\begin{tabular}{|c|c|c|c|c|c|c|}
\hline & \multicolumn{2}{|c|}{$\begin{array}{l}\text { Group } 1 \\
\text { Obese } \\
(n=56)\end{array}$} & \multicolumn{2}{|c|}{$\begin{array}{c}\text { Group } 2 \\
\text { Lean PCOS } \\
(n=56)\end{array}$} & \multicolumn{2}{|c|}{$\begin{array}{c}\text { Group } 3 \\
\text { Obese PCOS } \\
(n=43)\end{array}$} \\
\hline & $n$ & & $n$ & & $n$ & \\
\hline IFG/IGT & 6 & $10.7 \%$ & 5 & $8.9 \%$ & 9 & $20.9 \%$ \\
\hline Increased baseline insulin & 28 & $50.0 \%$ & 5 & $8.9 \%$ & 29 & $67.4 \%$ \\
\hline $\begin{array}{l}\text { Elevation of IRI over } 100 \mathrm{mU} / \mathrm{L} \text { on the } \\
60 \mathrm{~min} \text { of OGTT }\end{array}$ & 26 & $46.4 \%$ & 9 & $16.1 \%$ & 27 & $62.8 \%$ \\
\hline $\begin{array}{l}\text { Elevation of IRI over } 100 \mathrm{mU} / \mathrm{L} \text { on the } \\
120 \mathrm{~min} \text { of OGTT }\end{array}$ & 12 & $21.4 \%$ & 5 & $8.9 \%$ & 11 & $25.5 \%$ \\
\hline $\begin{array}{l}\text { Elevation of IRI over } 100 \mathrm{mU} / \mathrm{L} \text { on the } 60 \\
\text { and/or } 120 \mathrm{~min} \text { of OGTT }\end{array}$ & 29 & $51.8 \%$ & 10 & $17.9 \%$ & 27 & $62.8 \%$ \\
\hline $\begin{array}{l}\text { Elevation of IRI over } 100 \mathrm{mU} / \mathrm{L} \text { on the } 60 \\
\text { and } 120 \mathrm{~min} \text { of OGTT }\end{array}$ & 9 & $16.1 \%$ & 4 & $7.1 \%$ & 11 & $25.6 \%$ \\
\hline $\begin{array}{l}\text { Elevation of IRI more than } 5 \text { times over the } \\
\text { baseline (\%) }\end{array}$ & 39 & $69.6 \%$ & 40 & $71.4 \%$ & 29 & $67.4 \%$ \\
\hline $\begin{array}{l}\text { Decreased baseline glucose/insulin ratio } \\
(<0.333 \mathrm{mmol} / \mathrm{L} / \mathrm{mU} / \mathrm{L})\end{array}$ & 30 & $53.6 \%$ & 12 & $21.4 \%$ & 29 & $67.4 \%$ \\
\hline Increased HOMA-index & 39 & $69.6 \%$ & 17 & $30.4 \%$ & 37 & $86.0 \%$ \\
\hline
\end{tabular}

for PCOS, obesity tends to worsen it and the metabolic disturbances [29]. Our data support this theory and show that the indices of carbohydrate metabolism-fasting blood glucose and blood glucose on $60 \mathrm{~min}$ of OGTT and IRI on 0,60 , and $120 \mathrm{~min}$ of OGTT and HOMA index are significantly lower in lean PCOS subjects but do not differ significantly in obese and obese PCOS women although obese PCOS patients have higher mean values. This is why it can be postulated that the obesity and PCOS worsen their unwanted effects on the carbohydrate metabolism and lean PCOS women have comparatively discrete disturbances.

Our data show that the metabolic indices, SBP, DBP, and hematological results are highly dependent on the presence of obesity and not on the presence of PCOS in the patients. The hyperinsulinemia has an important role in the development of hypertension by increasing the sodium retention [30], and in this way, it leads to increased intracellular levels of sodium and calcium [31]. Insulin also increases the release of IGF-1, which can lead to hypertension as a result of nonstriated-muscle hypertrophy. We found a correlation between IRI during OGTT and systolic and diastolic blood pressure.

Many patients with PCOS have classical signs of metabolic syndrome. In healthy women with normal body weight and preserved insulin sensitivity, the adipocytes release small amounts of free fatty acids (FFAs) and have a normal activity of the lipoprotein lipase (LPL). In these women, the physiological levels of testosterone act in synchrony with the insulin and suppress the release of FFA, so they have antilipolytic effect [32]. In women with obesity, there is an increased production of FFA and decreased activity of LPL as a result of the prominent insulin resistance. In these conditions, the high androgen levels additionally worsen the disturbances in the lipid metabolism [32]. It is thought that approximately $70 \%$ of the patients with PCOS have disturbances in serum lipid levels [33]. Even after weight adjustment, the lipid abnormalities persist $[10,34]$. In our study, we found differences in HDL, VLDL, and TG between the lean PCOS patients and the other two groups.

There are data that the total white blood cell count is an independent risk factor for coronary heart disease $[35,36]$ and related to it morbidity and mortality [37]. In some studies in women with PCOS, there are higher WBC levels than in healthy women that correlate well with the markers of insulin resistance (HOMA index) [38]. We also found correlation between WBC and VLDL and TG-levels that promote the development of atherosclerosis. We found significantly higher levels of ESR in obese compared to lean PCOS patients. ESR showed positive correlation to BMI, WHR, WSR, and HOMA index. To our knowledge, this is the first study that assesses the ESR in PCOS patients. The increased levels of white blood cells and ESR are probably linked to subclinical inflammation that plays an important role in early clinical manifestation of atherosclerosis.

Testosterone stimulates the hematopoiesis in the bone marrow and, consequently, increases the hematocrit [39]. Hypogonadal men have a statistically significant lower hematocrit [40]. In accordance to this, we found a weak correlation between the levels of testosterone but not with other androgens to hemoglobin and hematocrit levels. In our study, lean and obese PCOS patients do not significantly differ in their testosterone levels and that is why they have similar blood count indices. On the other hand, obese PCOS patients have higher testosterone than obese women without PCOS and that goes with significantly higher hemoglobin but not hematocrit. It is important to note that hemoglobin and hematocrit correlate with testosterone but not with other androgen levels.

The indices of clinical hyperandrogenism are the highest in the obese PCOS patients and this confirms the theory 
that obesity worsens the disturbances caused by PCOS and aggravates the clinical presentation of the syndrome.

The family history for obesity is more frequent in obese patients no mater if they have PCOS or not. On the other hand, the family history for PCOS is more frequent in lean PCOS women and this suggests the more important role of the genetic milieu in these cases. Unlike that for obese PCOS women, probably of utmost importance is the presence of obesity. Studies show higher prevalence of diabetes mellitus in relatives of PCOS patients $[41,42]$ and particularly of those with impaired glucose tolerance or overt diabetes [43]. We found a higher rate of family history for diabetes only in obese PCOS patients. These patients also have notably higher family history of coronary heart disease that can be related to the increased cardiovascular risk in later life.

The absolute waist circumference $(>88 \mathrm{~cm})$ and the WHR $(>0.85)$ are both used as measures of central obesity in women [44]. Recently, another measure of central obesity was proposed which has shown superiority to BMI in predicting cardiovascular disease risk is the waist-tostature ratio (WSR), where a ratio of $\geq 0.5$ (i.e., a waist circumference at least half of the individual's height) is predictive of increased risk [45]. In light of concerns raised about the ability of BMI alone to predict cardiovascular risk, some studies have recently attempted to compare BMI with waist circumference and other anthropometric measures of obesity, such as WHR and WSR, as predictors for cardiovascular risk. In a meta-analysis of abdominal obesity indices comparing BMI, waist circumference, WHR, and WSR, researchers concluded that WSR was the best predictor for both hypertension and dislipidemia for both men and women, while BMI was the least accurate predictor of hypertension [46]. To our knowledge, our study is the first to show that WSR is a better marker for unfavorable metabolic profile (OGTT results, blood pressure, and lipid profile) than WHR in a specific group of PCOS patients. Further large-scale studies are necessary to position the different anthropometric parameters, according to definite endpoints.

Our results confirm the presence of insulin resistance both in lean and obese PCOS women that is, however, more pronounced in obese subjects. According to our data, the increased baseline insulin is much more sensitive in patients with obesity with or without PCOS than the standard OGTT without IRI measurement regarding the carbohydrate metabolism disturbances. This is not seen in lean PCOS subjects where the rate of IFG/IGT is the same as that of increased baseline insulin. In our previous study, it was shown that IGT and/or diabetes on 120 min of OGTT was diagnosed in $8.5 \%$ of the women with PCOS while IFG and/or diabetes on 0 min of OGGT-only in $2.2 \%$ of the patients [47]. In the present study, however, patients with diabetes were excluded, but in the whole population with OGTT, $12.9 \%$ had disglycemia-IFG and/or IGT.

In the three groups, insulin resistance according to the criteria of IRI over $100 \mathrm{mU} / \mathrm{L}$ during the OGTT is seen two times more frequently on $60 \mathrm{~min}$ than on $120 \mathrm{~min}$. So, if for some reason only two measurements of IRI during the OGTT are available, they must be on 0 and $60 \mathrm{~min}$ and not on 0 and $120 \mathrm{~min}$. This is mostly true for lean PCOS patients because in the other two groups the diagnostic powers of the increased baseline insulin levels are comparable to the response of the insulin on $60 \mathrm{~min}$ and exceed that on the $120 \mathrm{~min}$.

As to the HOMA index, its ability to diagnose the insulin resistance is highest in obese PCOS patients and lowest in lean PCOS patients. That is true also for decreased glucose/insulin ratio.

Limitations. Our study has all the limitations of retrospective crossectional studies-lack of all data for each patient, different clinical approach during the different periods, and so forth.

\section{Conclusion}

(1) Obesity is the most important factor for unfavorable metabolic and cardiovascular risk profile in PCOS patients.

(2) In our study population, WSR is a better anthropometric marker of adverse metabolic profile in women with PCOS and/or obesity than WHR.

(3) Carbohydrate metabolism testing is necessary in all PCOS patients because of the high prevalence of its disturbances.

(4) In patients with obesity with or without PCOS only the baseline indices-glucose and IRI and HOMA index can be used.

(5) In lean PCOS patients, an OGTT with IRI measurement on 0,60 , and $120 \mathrm{~min}$ is highly recommended.

(6) ESR show positive correlation with BMI and the indices of insulin resistance, but not with androgen levels.

\section{Conflict of Interests}

The authors declare no conflict of interests.

\section{References}

[1] M. Asunción, R. M. Calvo, J. L. San Millá, J. Sancho, S. Avila, and H. F. Escobar-Morreale, "A prospective study of the prevalence of the polycystic ovary syndrome in unselected Caucasian women from Spain," Journal of Clinical Endocrinology and Metabolism, vol. 85, no. 7, pp. 2434-2438, 2000.

[2] E. S. Knochenhauer, T. J. Key, M. Kahsar-Miller, W. Waggoner, L. R. Boots, and R. Azziz, "Prevalence of the polycystic ovary syndrome in unselected black and white women of the Southeastern United States: a prospective study," Journal of Clinical Endocrinology and Metabolism, vol. 83, no. 9, pp. 3078-3082, 1998.

[3] R. S. Legro, A. R. Kunselman, W. C. Dodson, and A. Dunaif, "Prevalence and predictors of risk for type 2 diabetes mellitus and impaired glucose tolerance in polycystic ovary syndrome: a prospective, controlled study in 254 affected women," Journal of Clinical Endocrinology and Metabolism, vol. 84, no. 1, pp. 165-169, 1999.

[4] J. E. Nestler, "Role of hyperinsulinemia in the pathogenesis of the polycystic ovary syndrome, and its clinical implications," 
Seminars in Reproductive Endocrinology, vol. 15, no. 2, pp. 111122, 1997.

[5] J. E. Nestler and D. J. Jakubowicz, "Lean women with polycystic ovary syndrome respond to insulin reduction with decreases in ovarian P450c17 $\alpha$ activity and serum androgens," Journal of Clinical Endocrinology and Metabolism, vol. 82, no. 12, pp. 4075-4079, 1997.

[6] J. E. Nestler and D. J. Jakubowicz, "Decreases in ovarian cytochrome $\mathrm{P} 450 \mathrm{c} 17 \alpha$ activity and serum free testosterone after reduction of insulin secretion in polycystic ovary syndrome," New England Journal of Medicine, vol. 335, no. 9, pp. 617-623, 1996.

[7] D. A. Ehrmann, R. B. Barnes, R. L. Rosenfield, M. K. Cavaghan, and J. Imperial, "Prevalence of impaired glucose tolerance and diabetes in women with polycystic ovary syndrome," Diabetes Care, vol. 22, no. 1, pp. 141-146, 1999.

[8] R. S. Legro, A. R. Kunselman, W. C. Dodson, and A. Dunaif, "Prevalence and predictors of risk for type 2 diabetes mellitus and impaired glucose tolerance in polycystic ovary syndrome: a prospective, controlled study in 254 affected women," Journal of Clinical Endocrinology and Metabolism, vol. 84, no. 1, pp. 165-169, 1999.

[9] P. Björntorp, “The android woman — a risky condition," Journal of Internal Medicine, vol. 239, no. 2, pp. 105-110, 1996.

[10] J. Vrbáková, R. Cífková, A. Jirkovská et al., “Cardiovascular risk factors in young Czech females with polycystic ovary syndrome," Human Reproduction, vol. 18, no. 5, pp. 980-984, 2003.

[11] E. Talbott, D. Guzick, A. Clerici et al., "Coronary heart disease risk factors in women with polycystic ovary syndrome," Arteriosclerosis, Thrombosis, and Vascular Biology, vol. 15, no. 7, pp. 821-826, 1995.

[12] E. Talbott, A. Clerici, S. L. Berga et al., "Adverse lipid and coronary heart disease risk profiles in young women with polycystic ovary syndrome: results of a case-control study," Journal of Clinical Epidemiology, vol. 51, no. 5, pp. 415-422, 1998.

[13] R. A. Wild, P. Alaupovic, and I. J. Parker, "Lipid and apolipoprotein abnormalities in hirsute women: the association with insulin resistance," American Journal of Obstetrics and Gynecology, vol. 166, no. 4, pp. 1191-1197, 1992.

[14] R. A. Wild, "Obesity, lipids, cardiovascular risk, and androgen excess," American Journal of Medicine, vol. 98, no. 1 A, pp. 27S32S, 1995.

[15] G. Paradisi, H. O. Steinberg, A. Hempfling et al., "Polycystic ovary syndrome is associated with endothelial dysfunction," Circulation, vol. 103, no. 10, pp. 1410-1415, 2001.

[16] K. Lakhani, N. Constantinovici, W. M. Purcell, R. Fernando, and P. Hardiman, "Internal carotid-artery response to 5\% carbon dioxide in women with polycystic ovaries," Lancet, vol. 356, no. 9236, pp. 1166-1167, 2000.

[17] C. J. Kelly, A. Speirs, G. W. Gould, J. R. Petrie, H. Lyall, and J. M. C. Connell, "Altered vascular function in young women with polycystic ovary syndrome," Journal of Clinical Endocrinology and Metabolism, vol. 87, no. 2, pp. 742-746, 2002.

[18] R. Azziz, K. S. Woods, R. Reyna, T. J. Key, E. S. Knochenhauer, and B. O. Yildiz, "The prevalence and features of the polycystic ovary syndrome in an unselected population," Journal of Clinical Endocrinology and Metabolism, vol. 89, no. 6, pp. 27452749, 2004.

[19] A. H. Balen, G. S. Conway, G. Kaltsas et al., "Polycystic ovary syndrome: the spectrum of the disorder in 1741 patients," $\mathrm{Hu}$ man Reproduction, vol. 10, no. 8, pp. 2107-2111, 1995.
[20] C. J. Glueck, S. Dharashivkar, P. Wang et al., "Obesity and extreme obesity, manifest by ages 20-24 years, continuing through 32-41 years in women, should alert physicians to the diagnostic likelihood of polycystic ovary syndrome as a reversible underlying endocrinopathy," European Journal of Obstetrics Gynecology and Reproductive Biology, vol. 122, no. 2, pp. 206-212, 2005.

[21] T. Apridonidze, P. A. Essah, M. J. Iuorno, and J. E. Nestler, "Prevalence and characteristics of the metabolic syndrome in women with polycystic ovary syndrome," Journal of Clinical Endocrinology and Metabolism, vol. 90, no. 4, pp. 1929-1935, 2005.

[22] T. Douchi, H. Ijuin, S. Nakamura, T. Oki, S. Yamamoto, and Y. Nagata, "Body fat distribution in women with polycystic ovary syndrome," Obstetrics and Gynecology, vol. 86, no. 4, pp. 516519, 1995.

[23] P. Acien, F. Quereda, and P. Matallin, "Insulin, androgens, and obesity in women with and without polycystic ovary syndrome: a heterogeneous group of disorders," Fertility and Sterility, vol. 72, no. 1, pp. 32-40, 1999.

[24] D. R. Haun, F. J. Pitanga, and I. Lessa, "Waist-height ratio compared with other anthropometric indicators of obesity as a predictor of high coronary risk," Revista da Associacao Medica Brasileira, vol. 55, no. 6, pp. 705-711, 2009.

[25] H. J. Schneider, H. Glaesmer, J. Klotsche et al., "Accuracy of anthropometric indicators of obesity to predict cardiovascular risk," Journal of Clinical Endocrinology and Metabolism, vol. 92, no. 2, pp. 589-594, 2007.

[26] A. Gambineri, C. Pelusi, V. Vicennati, U. Pagotto, and R. Pasquali, "Obesity and the polycystic ovary syndrome," International Journal of Obesity and Related Metabolic Disorders, vol. 26, no. 7, pp. 883-896, 2002.

[27] R. J. Norman, M. J. Davies, J. Lord, and L. J. Moran, “The role of lifestyle modification in polycystic ovary syndrome," Trends in Endocrinology and Metabolism, vol. 13, no. 6, pp. 251-257, 2002.

[28] B. O. Yildiz, E. S. Knochenhauer, and R. Azziz, "Impact of obesity on the risk for polycystic ovary syndrome," Journal of Clinical Endocrinology and Metabolism, vol. 93, no. 1, pp. 162$168,2008$.

[29] P. Vigil, P. Contreras, J. Alvarado, A. Godoy, A. Salgado, and M. Cortés, "Evidence of subpopulations with different levels of insulin resistance in women with polycystic ovary syndrome," Human Reproduction, vol. 22, no. 11, pp. 2974-2980, 2007.

[30] I. Zavaroni, P. Coruzzi, L. Bonini et al., "Association between salt sensitivity and insulin concentrations in patients with hypertension," American Journal of Hypertension, vol. 8, no. 8, pp. 855-858, 1995.

[31] L. M. Resnick, "Cellular calcium and magnesium metabolism in the pathophysiology and treatment of hypertension and related metabolic disorders," American Journal of Medicine, vol. 93, no. 2 A, pp. 11S-20S, 1992.

[32] R. Pasquali and A. Gambineri, "Mechanisms and treatment of obesity in PCOS," in From the Ovary to the Pancreas: Current Concepts and Controversies in the Polycystic Ovary Syndrome Totowa, A. Dunaif, R. J. Chang, S. Franks et al., Eds., Humana Press, Totowa, NJ, USA, 2006.

[33] “Third Report of the National Cholesterol Education Program (NCEP) Expert panel on detection, evaluation, and treatment of high blood cholesterol in adults (Adult Treatment Panel III) final report," Circulation, vol. 106, no. 25, pp. 3143-3421, 2002.

[34] K. J. Mather, F. Kwan, and B. Corenblum, "Hyperinsulinemia in polycystic ovary syndrome correlates with increased 
cardiovascular risk independent of obesity," Fertility and Sterility, vol. 73, no. 1, pp. 150-156, 2000.

[35] J. Danesh, R. Collins, P. Appleby, and R. Peto, "Association of fibrinogen, C-reactive protein, albumin, or leukocyte count with coronary heart disease: meta-analyses of prospective studies," Journal of the American Medical Association, vol. 279, no. 18, pp. 1477-1482, 1998.

[36] K. L. Margolis, J. E. Manson, P. Greenland et al., "Leukocyte count as a predictor of cardiovascular events and mortality in postmenopausal women: the Women's Health Initiative Observational Study," Archives of Internal Medicine, vol. 165, no. 5, pp. 500-508, 2005.

[37] B. D. Horne, J. L. Anderson, J. M. John, Intermountain Heart Collabarative Study Group et al., "Which white blood cell subtypes predict increased cardiovascular risk?" Journal of the American College of Cardiology, vol. 45, no. 10, pp. 1638-1643, 2005.

[38] F. Orio Jr., S. Palomba, T. Cascella et al., "The increase of leukocytes as a new putative marker of low-grade chronic inflammation and early cardiovascular risk in polycystic ovary syndrome," Journal of Clinical Endocrinology and Metabolism, vol. 90, no. 1, pp. 2-5, 2005.

[39] N. T. Shahidi, "Androgens and erythropoiesis," New England Journal of Medicine, vol. 289, no. 2, pp. 72-80, 1973.

[40] V. Bhatia, A. Chaudhuri, R. Tomar, S. Dhindsa, H. Ghanim, and P. Dandona, "Low testosterone and high C-reactive protein concentrations predict low hematocrit in type 2 diabetes," Diabetes Care, vol. 29, no. 10, pp. 1-6, 2006.

[41] T. Sir-Petermann, B. Angel, M. Maliqueo, F. Carvajal, J. L. Santos, and F. Pérez-Bravo, "Prevalence of Type II diabetes mellitus and insulin resistance in parents of women with polycystic ovary syndrome," Diabetologia, vol. 45, no. 7, pp. 959996, 2002.

[42] B. O. Yildiz, H. Yarali, H. Oguz, and M. Bayraktar, "Glucose intolerance, insulin resistance, and hyperandrogenemia in first degree relatives of women with polycystic ovary syndrome," Journal of Clinical Endocrinology and Metabolism, vol. 88, no. 5, pp. 2031-2036, 2003.

[43] D. A. Ehrmann, K. Kasza, R. Azziz, R. S. Legro, and M. N. Ghazzi, "Effects of race and family history of type 2 diabetes on metabolic status of women with polycystic ovary syndrome," Journal of Clinical Endocrinology and Metabolism, vol. 90, no. 1, pp. 66-71, 2005.

[44] S. Yusuf, S. Hawken, S. Ônpuu et al., "Effect of potentially modifiable risk factors associated with myocardial infarction in 52 countries (the INTERHEART study): case-control study," Lancet, vol. 364, no. 9438, pp. 937-952, 2004.

[45] K. M. Knowles, L. L. Paiva, S. E. Sanchez et al., "Waist circumference, body mass index, and other measures of adiposity in predicting cardiovascular disease risk factors among peruvian adults," International Journal of Hypertension, vol. 2011, Article ID 931402, 10 pages, 2011.

[46] C. M. Y. Lee, R. R. Huxley, R. P. Wildman, and M. Woodward, "Indices of abdominal obesity are better discriminators of cardiovascular risk factors than BMI: a meta-analysis," Journal of Clinical Epidemiology, vol. 61, no. 7, pp. 646-653, 2008.

[47] M. Orbetsova, V. Orbetsova, Z. Kamenov et al., "Comparative diagnostic characteristics of carbohydrate metabolism disorders in women with polycystic ovary syndrome (PCOS)," Akush Ginekol, vol. 42, no. 4, pp. 10-5-15, 2003. 


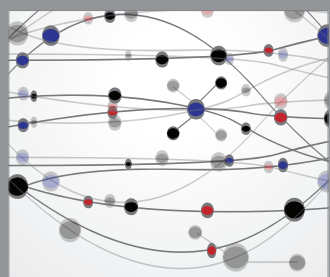

The Scientific World Journal
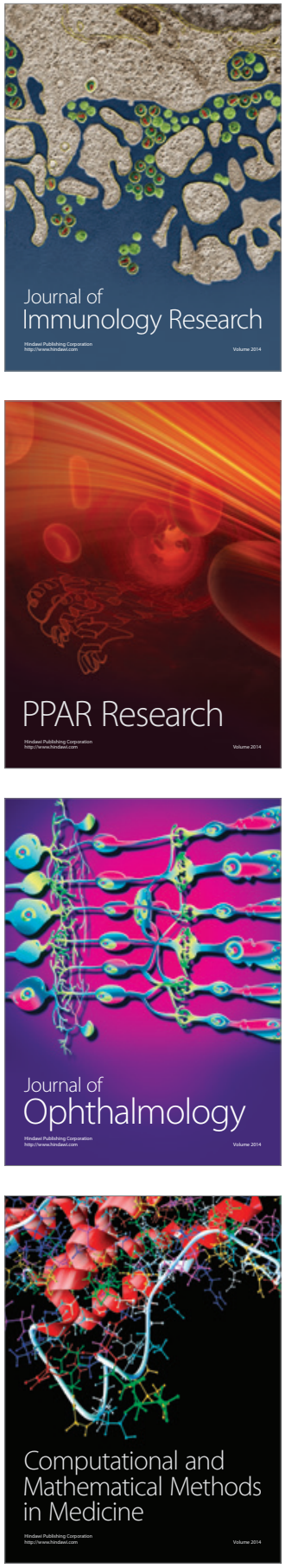

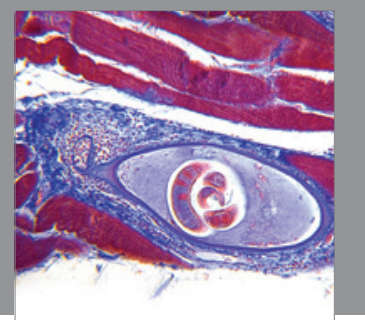

Gastroenterology

Research and Practice
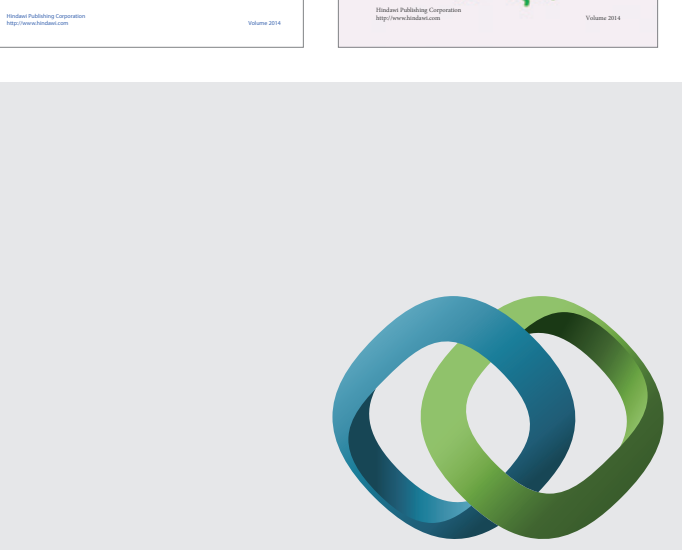

\section{Hindawi}

Submit your manuscripts at

http://www.hindawi.com
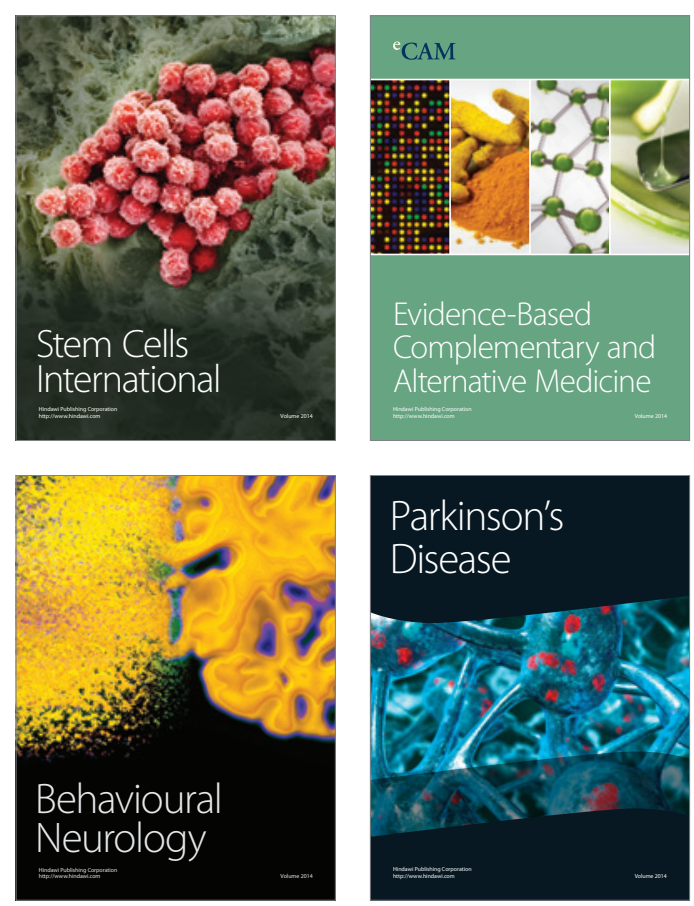

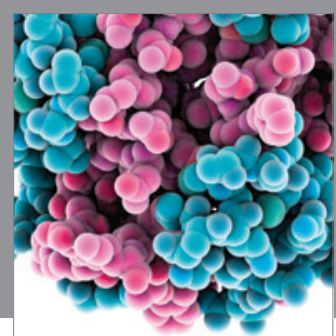

Journal of
Diabetes Research

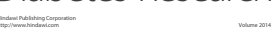

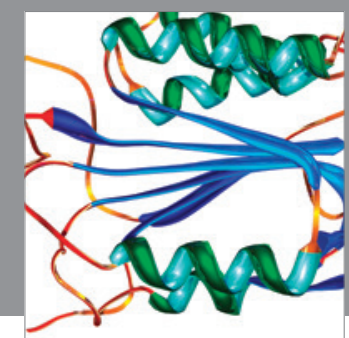

Disease Markers
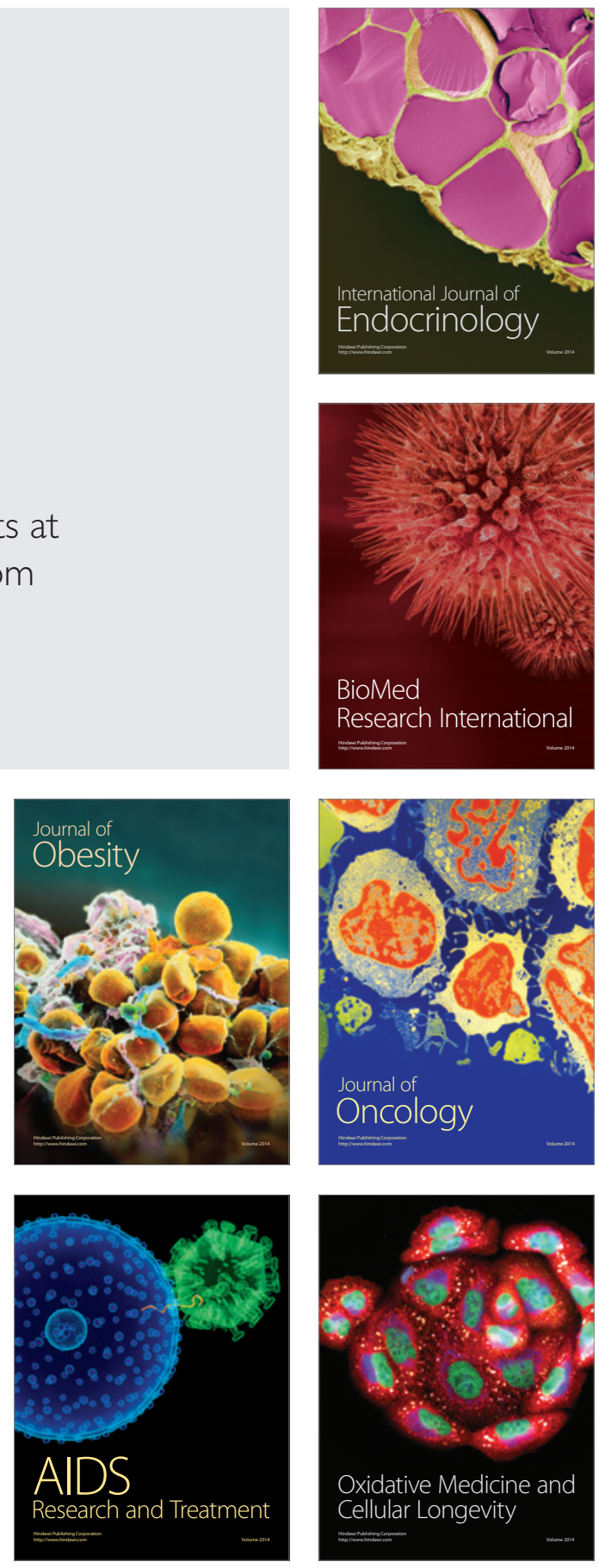